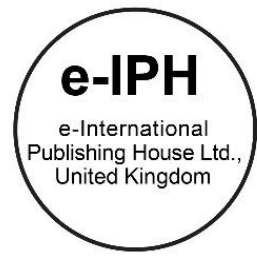

\title{
Students' Quality Learning Experience: Key to further studies in the same university
}

\author{
Mazni Saad*, Rosita Husain, Wan Nurul Fatimah Wan Mohamad Nawi, Nafiza Mahyuddin \\ Faculty of Business and Accountancy, Universiti Selangor, Shah Alam, 40000 Selangor, Malaysia
}

\begin{abstract}
This study investigates the expected learning experience that determines their desire to further their studies at the same university. A cross sectional analysis was done on 190 undergraduate students in a public higher learning institution. Their opinions were sought regarding the present quality of services offered by the university. The students were very concerned about the quality of teaching, their lecturers and the facilities on offer, and more so the course fees structure, technology, and support systems. There is a need to look again at some of the major complaints addressed, which could guarantee the return of these students to its doorstep.
\end{abstract}

Keywords: Satisfaction; learning experience; quality services; private university; Malaysia.

ISSN: 2398-4287@ 2017. The Authors. Published for AMER ABRA by e-International Publishing House, Ltd., UK. This is an open access article under the CC BYNC-ND license (http://creativecommons.org/licenses/by-nc-nd/4.0/). Peer-review under responsibility of AMER (Association of Malaysian Environment-Behaviour Researchers), ABRA (Association of Behavioural Researchers on Asians) and cE-Bs (Centre for Environment-Behaviour Studies), Faculty of Architecture, Planning \& Surveying, Universiti Teknologi MARA, Malaysia.

\subsection{Introduction}

In a dynamic competitive environment, a private university or private higher learning institution has to sustain and strengthen its competitive perimeters. It needs to ensure that its customers especially the students are happy and satisfied and that coming back for further studies is the normal thing to do. Thus, the voice of the customer is the one selling point that will give the university a competitive edge.

A university's main income largely depends on student fees, but growing numbers of private universities have made it difficult for one to get a bigger piece of the cake. Retaining students for continued studies every semester has now become even more challenging during this slow economic growth. At the same time, students in private higher learning institutions aim towards performing better every semester so that by continually achieving good results they would be able to minimize the amount of money they owe scholarship funders after completing a foundation or diploma program. When this happens, it is very likely that a private higher learning institution would lose existing students who are now able to further their studies in any recognized public higher learning institution that not only offers a "good brand," but does so with cheaper course fees.

The purpose of current study is interested in learning all about the kind of quality learning that would bring the greatest satisfaction to every student in the higher learning institution to the extent that they would want to come back for more. Hence, this study objective is to investigate the expected quality learning experience of private higher learning institution students and specifically aims to understand what learning experience determines their desire to further their education at the same university.

\footnotetext{
* Corresponding author. Tel.: +6-017-878-7543

E-mail address: maznisaad@unisel.edu.my
}

ISSN: 2398-4287@ 2017. The Authors. Published for AMER ABRA by e-International Publishing House, Ltd., UK. This is an open access article under the CC BYNC-ND license (http://creativecommons.org/licenses/by-nc-nd/4.0/). Peer-review under responsibility of AMER (Association of Malaysian Environment-Behaviour Researchers), ABRA (Association of Behavioural Researchers on Asians) and cE-Bs (Centre for Environment-Behaviour Studies), Faculty of Architecture, Planning \& Surveying, Universiti Teknologi MARA, Malaysia.

DOI: http://dx.doi.org/10.21834/e-bpj.v2i5.667 


\subsection{Literature Review}

\subsection{Satisfaction}

A private higher learning institution will always try to create the best learning environment that fosters successful students who are excellent academically and loyal to the university. This ensures that excellent academic performance is a priority in maintaining a high level of acceptance and satisfaction among the students. Satisfaction here refers to several definitions. Oliver (2010) states that satisfaction can be defined as feedback from a consumer, that results from the accomplishment of some expectations. It is an evaluation of a product or service feature or the product or services itself that provide an acceptable level of consumption related to fulfillment, including the level of under or over fulfillment. While Stoica, Radu, Dobrescu, and Orzan (2014) describes satisfaction as referring to a consumer's statement of quality experience; while using or after using a product or service in comparison to their expectations before consuming the product or service. Ene and Özkaya (2014) describes satisfaction from a customer's perspective; that it depends on the comparison of the client of what they have obtained from their expectations before experiencing it. This means that if customers' experience meets their expectations, they will be satisfied; if not, they feel disappointed and will not be satisfied. Furthermore, if the presented features are above their expectations, the customer will be delightful. Therefore, satisfaction only can be obtained after consumption as a result of evaluating the performance of the product or service before and after the service has been performed. There are certain points in common among the authors; that their emotional reaction influences consumer satisfaction, and their thoughts and expectations towards their perception of the product or service performance resulting from consumer experience at certain points of time.

\subsection{Entities in Higher Education Institutions}

Today higher education institutions are beginning to realize that their entities represent a business-like service industry and that they are therefore being forced to attract students' satisfaction. These institutions are starting to focus more on meeting or even exceeding the needs of their students (Gruber, Fuß, Voss, \& Glaeser-Zikuda, 2010). It has also resulted in scholars measuring learning experiences in a higher learning institution. Recent studies by Hanssen and Solvoll (2015); Butt and Rehman (2010); and Hussain et al. (2014) highlight the importance of facility and technology, lecturers' expertise, and management and interpersonal support towards students' satisfaction.

\subsubsection{Facilities and Technology}

Facilities and technologies are fast becoming important entities in any education system nowadays. According to Gruber (2010), institutions of higher learning have been focusing on these two variables and have adopted them as part of their market-oriented strategies that differentiate them from their competitors. Hanssen and Solvoll (2015) investigated satisfaction towards facility among several small universities of Norway. A survey of 5232 with a response rate of $28 \%$ brought about only positive outcomes. The study reveals that reputation, cost, job prospects, the host city, study hall, group work, auditorium, social areas, and computer access greatly affected students' satisfaction. However, the multiple regression results demonstrate that although social areas and satisfaction were strongly associated, the perception of library and computer accessibility did not support the research objectives. Another similar investigation from Thailand studied factors affecting students' intentions to study at universities by adopting the "student-as-customer" concept. From 318 responses, the SEM AMOS shows that all variables were supported except for ease of course achievement towards attitudes.

Therefore, recent studies of both small and large higher learning institution students indicate that generally, students' expectations are high. The outcomes of these studies also indicate that both structure and infrastructure are equally important in satisfying the students and in influencing their choice of a university. Students who are shaped by their frequent positive experience of "campus life," and also their studies would not only develop a good perception but also give a positive review of their learning experience. Such a perception and review could only be a good testimony for a higher learning institution and may attract potential students to further their studies at the University. Armed with the most powerful word-of-mouth communication for a marketing tool, the chance that current students would further their studies at the same higher learning institution would be very high.

Moreover, online facilities and technologies were recognized as important tools in motivating students (Oliver, 2010; Yuan \& Powell, 2013). Yuan and Powell (2013) have cited Belanger and Thomton (2013) for four categories of motivation. They are: (1) to support lifelong learning or gain an understanding of the subject matter, (2) for fun, entertainment, social experience, and intellectual stimulation, (3) convenience, and (4) to experience or explore purpose. In making course fees affordable, this initiative or approach is needed to enable higher learning institutions to develop their strengths to encourage more students to make a comeback. The same survey also indicates that students prefer online facilities as part of their choice and decision-making.

\subsubsection{Lecturers' Expertise}

Another significant university asset which has a major influence on overall student satisfaction is lecturers' expertise. The study by Butt and Rehman (2010) on higher education institution in Pakistan provides the evidence. Their study had a sample size of 350 students from different private and public universities and measured the influence of factors like teachers' expertise, courses offered, learning environment and classroom facilities on student satisfaction through an adapted questionnaire on a 5-point Likert scale. The results of regression analysis revealed that all the attributes have a significant and positive impact on student satisfaction in higher education although with varying degrees of strength. The authors concluded that lecturers' expertise is the most influential factor among all of the variables and therefore deserves the special attention of policymakers and institutes. A similar study conducted by 
Hussain, Jabbar, Hussain, Rehman, and Saghir (2014) compared students' satisfaction level towards both academic and nonacademic facilities in the universities of Azad Jammu and Kashmir. Their dissatisfaction towards these facilities was not comparable to that found among students in several universities of Punjab. In Punjab, the study was performed on two faculties, and it revealed that teachers' expertise was significant in one faculty but not the other. This study also showed that both faculties were satisfied with other variables like the library.

Martirosyan (2015) studied factors contributing to student satisfaction in Armenian public and private institutions of higher education. Data were collected in nine public and three private institutions located in different rural and urban areas of Armenia. The sample consisted of 372 students through a self-reported questionnaire from 12 institutions that geographically covered the whole country for a comparatively complete picture. Factors investigated about student satisfaction included: demographics, academic experience, faculty services, students support facilities, campus life, and social integration. This study revealed that faculty services such as the lecturers' expertise play a crucial role when it comes to overall student satisfaction in Armenian higher education. Students from private institutions reported a significantly higher satisfaction level than their peers at public institutions. Based on the above studies, the researcher can conclude that lecturers' expertise is one the most dominant variables that will influence the students' expectations of the quality learning experience at the higher learning institution.

\subsubsection{Management and Interpersonal Support}

Another variable that plays an important role in significantly influencing student satisfaction is support from the administrators of the higher learning institution. Oscar, Kara, and Kaynak (2005) studied the determinants of business students' satisfaction and retention level in higher education in South Central Pennsylvania. Applying Herzberg's two-factor theory, the study hypothesized that the quality of experience and relationship between a higher education institution and its society would enhance student satisfaction and retention. The theory reveals a symbolic relationship between the student, higher learning institution, and society as a whole. The study creates a model of student satisfaction and intentions that incorporates 18 independent variables, which represent six higher-order dimensions (faculty, staff advising, classes, student partial college experience, satisfaction, and intentions). Support management such as staff advising plays an essential role in the higher learning institution system since they serve to provide information and counseling for students, enabling them to proceed through higher learning institution in an efficient manner. Based on data collected from 160 undergraduate business students, the study used a path analysis to test the hypothesized effects. After incorporating a comprehensive set of independent variables and self-reported experiential assessments to predict experience, the results were finally related to student satisfaction. The study concluded that college students who have a positive experience are more likely to be satisfied with the college or university than students who do not have a positive experience.

In another study, Gruber et al. (2010) examined student satisfaction with higher education services using a combination of lecturers and students as their respondents. For data collection, the researcher distributed questionnaires to 8 lecturers for the pilot study and 18 lecturers for the main study. The response rate was 99\%, where 374 students (pilot study) and 544 students (main study) responded to the questionnaires. $76 \%$ (pilot study) and $80 \%$ (main study) of the participants were females, thus reflecting the gender distribution of teacher education students at the higher learning institution. Fifteen quality dimensions that covered most aspects of the students' life were discussed which included administrative and student services, the atmosphere among students, the attractiveness of the surrounding city, computer equipment, courses, library, lecturers, lecture theaters, refectory/cafeteria and many others. The study revealed that there was a positive relationship between student satisfaction and a stable person-environment. In conclusion, the present literature indicates that students are satisfied with the moderately perceived quality of service offered by the higher learning institution, as well as the conducive learning environment. Management support did influence the students' expectations, which eventually form a positive perception of the higher learning institution. It will increase the chances of the students remaining in the same higher learning institution to further their studies.

\subsection{Methodology}

This study investigated a pilot study on students' quality learning experience in a satellite campus of a private higher learning institution in Selangor. Specifically, the population targeted were final semester students from three selected programs who have completed a course in Quality Management. The three programs are Bachelor of Marketing, Business Management, and Human Resource Management. Non-probability sampling is deemed suitable and favorable for operational considerations. It is relevant because students from these three degree programs have taken a semester's study of a Quality Management course. The Quality Management syllabus requires the students to be familiar with aspects of quality so that they can demonstrate their understanding and ability when relating theory to real case applications.

Also, the satellite campus offers all programs that are in compliance with the Malaysian Qualifications Agency (MQA) requirements. All higher education program under MQA in Malaysia is responsible for quality assurance practices in ensuring relevancy, reliability, adaptability, and effectiveness to address the changing environment in which higher education operates. An open-ended survey was conducted among 190 undergraduate students of the three programs. As a result, this study offers only a descriptive analysis, which focussing on the entities that are mostly preferred by the students.

There are several limitations in this study. Firstly, a cross-sectional analysis of the sample was done at the same time to identify the final year students, whose opinions were then sought regarding the present quality of services offered by the higher learning institution. One of the other possible limitations is that the satellite campus in this study has reached limited capacity for an additional number of students due to space constraints. Besides, the university is in a state of transition, where air conditioners in all the 
buildings are being changed for new ones. Thus, the learning atmosphere in class is presently quite hot and uncomfortable due to a large number of students (ranging from 40-60 students) placed in each class at one period of time. Furthermore, the investigation is on case study base in one of the private higher learning institutions in Selangor.

\subsection{Findings}

\subsection{Overall Findings}

Figure 1 shows the demographic profile of 190 final year students. In this study, bachelor programs such as Marketing, Business Management, and Human Resource Management involved in this study. Out of these, more than $60 \%$ of the responses were received from students who enrolled in Human Resource Management. The second largest number of students (26\%) was from the Business Management program followed by Marketing (13\%). The main respondents were the female students $(66 \%)$.

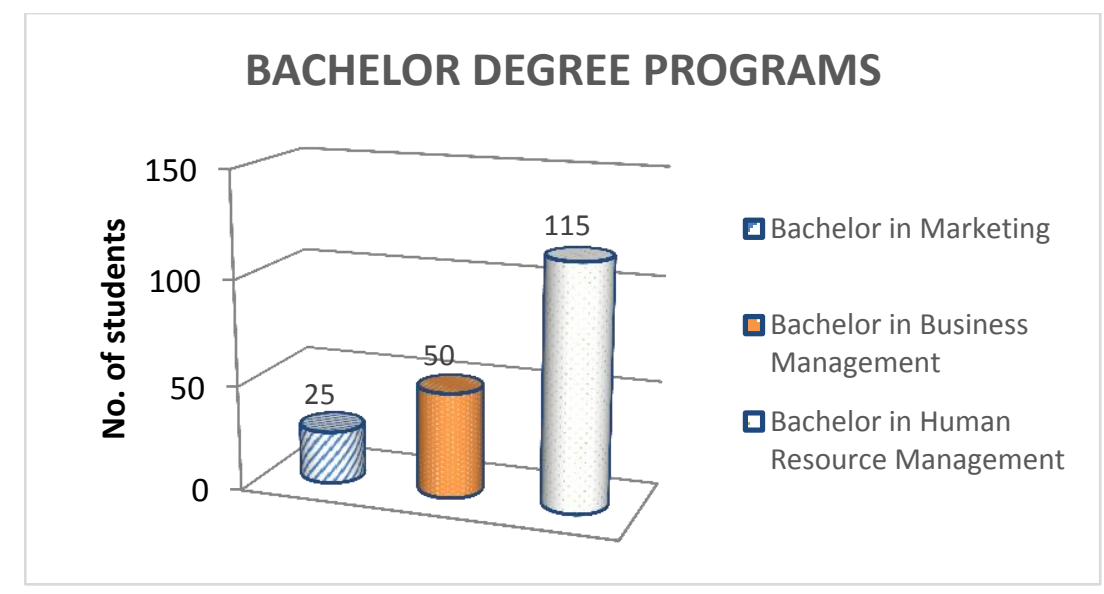

Figure 1: Bachelor Degree Programmes involved in the study

The 'voice of the customer' declares that students were very concerned not only with the quality of teaching, their lecturers and the facilities on offer, but more so the course fees structure, accreditation obtained for each course, technology, and support systems. Figure 2 presents the preferred entities students expect from the existing higher learning institution.



Figure 2: Preferred Entities

\subsection{Preferred Entities}

The open-ended question on the "suggested four (4) quality services to improve students' satisfaction" expected students to state their preferences as a higher learning institution student. As shown in Figure 2, almost half of the total respondents mentioned facilities. Respondent R0691 said, "students spared three to four years of their time in a registered course, so a clean and calm environment and even cheerful colors of buildings are necessary to attract students."

Specifically, $47.6 \%$ of the responses highlighted that the focus of the study should be towards maintaining air conditioning in each classroom, a clean cafeteria, a gymnasium, a bigger library space and parking lot (R1641 and R6881). The provision of sports 
facilities was also of great concern as it contributes to students keeping themselves healthy while enjoying academic life at the same time. Several respondents mentioned that a facility such as a lounge and a gym would stop students from leaving the university premises immediately after class (R6941) and that sports facilities can help decrease students' mental stress or pressure normally associated with assignments, quizzes, and tests (R2751). A comment on the physical environment facilities also includes having a comfortable classroom temperature. The cooling atmosphere was also linked to the minimal space in each of the classroom which usually had to accommodate an existing large number of students of 40 to 60 . The students claimed that a higher learning institution should provide a good study environment as it can only enhance students' learning focus. Among the many examples quoted in the survey, the following seemed most common - "the university should provide a peaceful and quite classroom condition with proper tables and chairs." A student (R6941) even claimed that facilities that can definitely "make students feel comfortable" are the "advanced and modern facilities" found inside as well as outside the classrooms, and that these are expected to have significant effects on students' concentration in class. Physical elements such as the arrangement of desks, seating structure, or intangible elements like temperature, on the other hand, can impact a student's active participation in class. Students further commented that "a conducive classroom should not necessarily be equipped with an air conditioner even though having one is a bonus. It should, in fact, be more about cleanliness and the overall experience of being in the classroom itself'. Poor air circulation too can bring about allergies that make students sluggish or inattentive in class. The higher learning institution can provide an environment-friendly campus to students in addition to a clean, safe and healthy environment by immediately removing potential distractions that de-motivate students from concentrating on their studies. Another factor that impacts students' satisfaction level with regards to facilities is linked to safety and security measures implemented in the university premises that will make them feel secure throughout the learning process. This includes the availability of fire management and CCTV equipment.

The second most emphasized entity obtained from the survey is the teaching environment. About $16 \%$ of the responses mentioned lecture styles and taught aids as factors of concern in fulfilling their overall satisfaction of their learning experience at the higher learning institution. Students pointed out that the use of visual aids such as displaying slideshows is the most common practice during lectures. It is also their preferred lecture mode as visuals more than words help them "stay focused in class." In other words, students find great difficulty in understanding and remembering lectures unless aided by visuals. As the Turkish saying goes, "if speaking is silver, then listening is gold," pointing out that since listening requires twice as much effort as speaking, it is, therefore, the lecturers' responsibility to facilitate, plan and strategize every opportunity in the classroom for learning. The survey acknowledges the students' preference for experienced lecturers who can deliver knowledge as well as share real working experiences. Respondent R1721 commented, "students might be lost in class when a lecturer is an inexperienced fresh graduate who has very little or no related experience to share with the students in class." Furthermore, survey respondents expected permanent staff to be more committed to spending more time with students, particularly during their assigned consultation hours. Another respondent (R7521) commented strongly on the need to reduce the number of part-time lecturers due mainly to their apparent "lack of commitment to the students." The university's management also receives yearly feedback on lectures given and should make attempts to work on them, particularly the complaints. In this following comment, the students also expected their yearly comments on lectures and lecturers to be reviewed and used as the basis for some action to be taken towards total satisfaction. The students suggested creative teaching methods which are also able to create lots of excitement among the students, "We want to focus and understand while the lecturer is delivering the subject. We feel happier coming to class because creative teaching approaches can increase our satisfaction in learning" (R2441). Respondent R6941 consistently commented that the "university should improve tools used in the classroom for teaching. Instead of using just books and notes to disseminate knowledge, lecturers could employ technologically advanced teaching tools to maximize quality teaching.

Another important influencing factor to satisfaction is administrative staff with excellent communication skills. To the students, the main role of administrative staff is not only to monitor students' overall condition, but also to have a rapport and a good relationship with the students" said R2651, "I experienced excellent customer service from the librarian who is good in communication and is very helpful to students at the counter. They are very polite, always smiling with students, and seem to enjoy assisting students in completing their assignments and thesis". About $10 \%$ of the students pointed out that they did expect the administrative staff to give useful information to the students and to treat them fairly. In their comments, "administrative staff should not have an angry face, and they must smile and be more patient while dealing with customers" (R1241). Students also mentioned that they realized making mistakes like delaying the registration of additional courses that may create extra work for the administrative staff. However, they still expect to be continuously guided with courtesy. This is consistent with respondent R0671 who said that students expect administrative staff to be willing to deal with them harmoniously and comfortably relationships because they are the only access for students to solve their problems related to the higher learning institution.

The current survey surprisingly highlighted concerns about course fees which are considered to be quite steep for the students, although comparatively proven by the university to be amongst the cheapest of private universities. Comments like, "students feel proud to be part of a university with a good reputation, but would like to enjoy some reward for showing loyalty like perhaps a reduction in fees." "I would also like to suggest that the university makes an effort to convince the ministry to look into the university's current needs with a better plan and budget" (R3271). Another respondent (R3521) said that "it was the university's cheaper fees that had driven me to register in the bachelor's degree program in the first place." However, "fees have to be compatible with the products and services on offer" (R1621). This comment is consistent with another given by the student, "affordable educational fees with excellent facilities and environment can help students become more passionate and efficient learners" (R1451). These comments are critical accounts of an education system that is no longer passive but has become a growing industry with lots of private universities on offer in the market. 
About the university's on-line system, its current usage of e-learning and e-library or student portal could be considered as insufficient due to difficulties related to out of campus accessibility (7\%). As such, to improve students' learning experience satisfaction; the university would have to upgrade its system to ensure "trouble-free access" for students. As for library needs, students expect to be provided with larger learning spaces and more materials for references. They added that "our university should provide more rooms for discussion and more personal computer units in the library." Besides, comments were also directed towards simplifying a more convenient and student-friendly "i-daftar (e-registration) procedure (R0691). Students would prefer an easy and efficient procedure for registration; one with fewer steps when completing one's registration. In one comment, "The system must assure a smooth, free registration period, where an easy and fast access can only increase our satisfaction towards the university" (R2441). A user-friendly registration is also expected while paying for examination fees because "waiting too long in a queue only makes many students unhappy. We should also be allowed to pay the fees by credit cards" (R1241).

Other preferred entities (as in Figure 2) refer to existing courses, the library, and environment. An interesting comment was received from $\mathrm{R} 1358$ which concluded the need for lecturers especially those with a Ph.D. to publish their books for classroom use. The students will then benefit from the reduced cost when buying such textbooks and references. R1358 made the following comment on university produced textbooks and related reference materials, "the university management can appoint lecturers especially those with doctorates to compile lecture notes, powerpoint slides, hand-outs, as well as relevant reading materials from other credible sources into reference manuals for student's use. This idea an excellent way to reduce not only cost but time spent on accessing and gathering reading materials ourselves."

As a conclusion, teaching facilities, library, internet access and the campus environment play a vital role in influencing students' satisfaction. This satisfaction will lead to their loyalty towards the university and a guarantee of a return to the same university for more academic pursuits.

\subsection{Discussion and Analysis}

This discussion begins with a recapitulation of four quality services derived from consistent comments made by most final semester undergraduate students involved in a survey conducted by this study. These students who have experienced at least three years of study in the university consider these as services that contribute to an increase in their satisfaction level towards their learning experience at the university. It is particularly relevant for students who wish to pursue a postgraduate education in the same university. Among the services are university facilities that appear to be of top priority. This finding is expected as a similar study conducted previously by Hanssen and Solvoll (2015) found that $34 \%$ of the variance in student satisfaction was with university facilities. The study also suggested that good quality facilities be inclusive of the course fees. Facilities often become a selling point for many universities, so naturally, they will portray the best facilities they have to catch the interest of the students and their parents. Hence, a higher learning institute must ensure that their marketing and promotion is undertaken in a sophisticated manner.

Teaching and learning experience is the university's cutting edge and distinguishes a well-planned and well-delivered academic program from one that is not. A lecturer represents a leadership role because they directly deal, guide, and teach the students. The literature review of studies by Hussain et al. (2014) and Butt and Rehman (2010) support the overall comments made by the students on the lecturers' expertise, which this study obtains throughout its open-ended survey. While some lecturers become a favorite to some students, a better teaching methodology in the class has now become a point of satisfaction for some other students (Arif, llyas, \& Hameed, 2013). As highlighted by Small, Dowell, and Simmons (2012) and Kim, Pederson, and Baldwin (2012), the adoption of online learning, for example, seems more effective and immediate when posting announcements and new materials to initiate synchronous (live, in real time) and asynchronous (ready when time permits) communication. The result of students' perception of a tutorial module via e-learning, for instance, confirms it as "easy to use," "easy to learn," satisfactorily fulfilled, and usefully perceived. Thus, the use of social media such as the e-mail or WhatsApp application is very much relevant in today's education set-up. Lecturers are also expected to attend basic courses such as pedagogy, outcome-based education (OBE), research methodology classes, and many more. Unlike a teacher who obtains proper guidance prior classroom teaching, lecturers are expected to attend not only courses but also conferences and seminars and become a member of as many relevant associations as possible so as to share new updates with the students. This active involvement means additional knowledge for the lecturer, which can later be used to help students achieve the desired grades in examinations.

Findings of the current study on management support show that students do not wish to have a bad experience with the university's administrative staff although some of the mistakes made do come from them. The student's expectations from the management group are high, which aligns well with a study by Koris and Nokelainen (2014). In their study, students expected to be treated as a customer. In fact, students wanted the management staff to inform them of any changes made as fast as possible and also help them to solve study problems. Students are an asset to the university; the existence of the institution is to serve the students, and therefore, the administrative staff may want to learn how to deal with the students with more sensitivity.

The earlier findings of the study suggest that there is a need to look again at some of the major complaints related to the existing fees, especially since the management has always considered it as the most reasonable offered so far by any private university. The findings also indicate that it is particularly imperative for a private university to ensure continuity of its business by improving some quality aspects of services that could guarantee the return of these students to its doorstep. This finding is consistent with those of Mazzarol and Soutar (2002). Although their research looked at 879 students studying abroad, tuition fees have always been the key motivating factor for a students' choice of enrolment in any university, locally or overseas. As such, aggressive initiatives must be tailored to the current dynamic economy, where the education industry is today a booming market force. With course fees becoming a 
primary source of income for a university, it, therefore, needs to develop a long-term relationship with its existing students instead of depending on new ones. This strategy would reduce cost to a higher cost for a university and would also probably generate more income through this new relationship life cycle.

The university should establish and enhance a strong bond with the students. When all the expected entities are fulfilled, students will have a strong belief and a positive perception and attitude of the institution. This will eventually create the much-needed loyalty and willingness to recommend the institution to others. After all, loyalty as mentioned by Fernandes, Ross, and Meraj (2013) is the overall program satisfaction $(\beta=0.507$ ) that consists of good teaching quality, organization and management of the program, academic support, and satisfaction with services and facilities $(\beta=0.248)$ that will contribute to student loyalty and their recommendation to others. Expectations, loyalty, and performance are closely connected. According to Armstrong, Kotler, and Opresnik (2017), the performance of a product that falls short of expectations will dissatisfy customers and vice versa; the customer is highly satisfied or delighted when performance exceeds expectations.

This study, however, is presenting the overall results in descriptive forms due to an exploratory study in nature. The results of the pilot investigation are to examine the feasibility of an approach that is intended to ultimately be used in a larger scale study in future.

\subsection{Conclusion and Recommendations}

This study concludes that learning experience is very crucial, and the ideas of these students must be taken into consideration for continual improvement. Overall, the students highlighted facilities as the most preferred entities followed by teaching environment to be considered that influence their learning experience. In sustaining a higher education business, a private university should conduct research on students' satisfaction to seek a list of variables that can make students happy. Interestingly, Based on the response majority students are satisfied with the quality of the lecturers, it just that the physical evidence that they concern with. Subsequently, students will rate services and management to analyze their level of satisfaction as customers. A host of programs from foundation to postgraduate is a bonus for the university when familiar students who are satisfied with their learning experience in the university decide to enroll into higher programs of study. This satisfaction would undoubtedly reduce marketing cost that could ultimately determine a fairer fee structure for the students. Furthermore, personal experience or satisfied students can benefit in several ways as explained by expectancy theory. The theory relates students' consistent behavior with their perceptions. Thus, the students are more likely to achieve higher grades and engage in positive word-of-mouth communication while continuing to collaborate with the institution after their graduation. This present study also recommends a similar approach to the wider population, which cover other programs including postgraduate programs in future research.

\section{Acknowledgements}

This research was partially funded by Universiti Selangor (UNISEL) through the Faculty of Business and Accountancy in Shah Alam, Selangor. The authors gratefully thank the UNISEL for awarding the permission to participate in the current conference. Special thanks are dedicated to all lecturers and students of Quality Management (PMS3383) in semester 41534 for their cooperation.

\section{References}

Arif, S., llyas, M., \& Hameed, A. (2013). Student satisfaction and impact of leadership in private universities. The TQM Journal, 25(4), 399-416.

Armstrong, G., Kotler, P., \& Opresnik, M. O. (2017). Marketing: An Introduction (13rd. edition ed.). London: Pearson Education Limited.

Butt, B. Z., \& Rehman, K. U. (2010). A study examining the students satisfaction in higher education. Procedia Social and Behavioral Sciences, 5.

Ene, S., \& Özkaya, B. (2014). A Study on Corporate Image, Customer Satisfaction and Brand Loyalty in the Context of Retail Stores. Asian Social Science, $10(14), 66$.

Fernandes, C., Ross, K., \& Meraj, M. (2013). Understanding student satisfaction and loyalty in the UAE HE sector. International Journal of Educational Management, 27(6), 613-630.

Gruber, T., Fuß, S., Voss, R., \& Glaeser-Zikuda, M. (2010). International Journal of Public Sector Management, $23(2), 105$ - 123.

Hanssen, T.-E. S., \& Solvoll, G. (2015). The importance of university facilities for student satisfaction at a Norwegian University. Facilities, 33(13/14), 744-759.

Hussain, S., Jabbar, M., Hussain, Z., Rehman, Z., \& Saghir, A. (2014). The Students' Satisfaction in Higher Education and its Important Factors: A Comparative Study between Punjab and AJ\&K, Pakistan. Research Journal of Applied Sciences, Engineering and Technology, 7(20), 4343-4348.

Kim, H. J., Pederson, S., \& Baldwin, M. (2012). Improving user satisfaction via a case-enhanced e-learning environment. Education and Training, 54(2/3), 204-218.

Koris, R., \& Nokelainen, P. (2014). The student-customer orientation questionnaire (SCOQ): Application of customer metaphor to higher education. International Journal of Educational Management, 29(1), 115-138.

Martirosyan, N. (2015). An examination of factors contributing to student satisfaction in Armenian higher education. International Journal of Educational Management, 29(2), 177-191. 
Saad M., et.al. / $5^{\text {th }}$ AicQoL2017Bangkok, 25-27 February 2017 / E-BPJ, 2(5), March 2017 (p.127-134)

Oliver, R. L. (2010). Satisfaction : A Behavioral Perspective on the Consumer (pp. 383). Retrieved from https://books.google.com.my/books?hl=en\&lr=\&id=TzrfBQAAQBAJ\&oi=fnd\&pg=PP1\&dq=satisfaction+oliver+2014\&ots=LoTxfVY7Ox\&sig=V254Fkox4gvrtqtB7gPcBLPs o00\&redir_esc=y\#v=onepage\&q=satisfaction\%20oliver\%202014\&f=false

Oscar, W. D. J., Kara, A., \& Kaynak, E. (2005). Determinants of business student satisfaction and retention in higher education: applying Herzberg's two-factor theory. International Journal of Educational Management, 19(2), 128-139.

Small, F., Dowell, D., \& Simmons, P. (2012). Teacher communication preferred over peer interaction: Student satisfaction with different tools in a virtual learning environment. Journal of International Education in Business, 5(2), 114-128.

Stoica, I., Radu, A.-C., Dobrescu, A., \& Orzan, O. A. (2014). Modelling User Satisfaction of Medical Educational Services. Annales Universitatis Apulensis Series Oeconomica, 16(1), 229-238.

Yuan, L., \& Powell, S. (2013). MOOCs and open education: Implications for higher education. Retrieved from http://publications.cetis.ac.uk/2013/667 